\title{
Sodium Sulfate Corrosion of Metro Tunnel Lining Concrete Strength Test Curve of Impact Study
}

\author{
Changzheng Sun ${ }^{1, a}$, Tiantian Sang ${ }^{1, b}$ and Jinke Zhang ${ }^{1, c}$ \\ ${ }^{1}$ School of Civil Engineering, Shenyang Jianzhu University, Shenyang 110168, China \\ a474670207@qq.com, ${ }^{b} 1321012017 @ q q . c o m,{ }^{c} 252036628 @ q q . c o m$
}

Keywords: Salt corrosion; Rebound method; Tunnel lining concrete

\begin{abstract}
The project adopt raw materials of Shenyang subway tunnel lining concrete to product 40 groups of tunnel lining concrete specimen. First of all investigating and analyzing the corrosion of subway tunnel lining concrete.Second determine the selection of sodium sulfate on tunnel lining concrete under dry-wet alternate accelerated corrosion test.The corrosion of tunnel lining concrete in the process of performance change was described. Through the non destructive testing(NDT) of rebound method detecting the strength of tunnel lining concrete after corrosion of sodium sulfate.We got mean relative error $\delta$ ) and relative standard error $\left(e_{\mathrm{r}}\right)$ inside the specification through linear function, power function and exponential function, quadratic polynomial function regression analysis on non destructive testing and damage testing. The regression results show that strength test curve has good applicability to the corrosion of tunnel lining concrete.Raising the strength formula of shenyang subway tunnel lining concrete subjected to corrosion test.
\end{abstract}

\section{Introduction}

The subway tunnel has large investment and high durability requirements, which has more than 100 years' design working life.Because of the subway tunnel lining concrete directly contact with external environment and underground environment and has special characteristic, which made the subway tunnel lining concrete structure subjected to damp environment and groundwater seepage pressure effect frequently ${ }^{[1-2]}$. With all kinds of corrosion impurities intrusion, tunnel lining concrete will suffer from corrosion damage in long term ${ }^{[4]}$. Strength testing had been timely made in corrosion of subway tunnel to ensure the safety of subway tunnel structure. There are many strength testing method.The core sampling method belong to distress detection, which due to cause further damage so in the test application is restricted. Ultrasonic method belong to nondestructive testing, which have many distinct advantages and very few report of strength testing on corrosion of tunnel lining concrete, which still belong to blank stage.

\section{Experimental materials}

Cement: C25 C30 tunnel lining concrete block using ordinary Portland cement; Fine aggregate: medium sand fineness modulus of 2.6; Coarse aggregate: particle size is $5 \sim 10 \mathrm{~mm}$ of continuous gradation limestone rubble; Water: test of water as ordinary tap water; Additive and admixture: JC - 2 early strength high-range water reducing agent and fly ash; Chemical reagent: Shenyang Xinhua reagent factory production of Na2SO4 reagents, in line with the "GB/T6009-2003 ", "GB672-78" requirements.

\section{Mix proportion design}

Table1 shows that the dosage of water, cement, sand and stone in subway tunnel lining concrete. Table2 shows that the dosage of admixture in subway tunnel lining concrete.

Table1 Mix ratio of subway tunnel lining concrete 


\begin{tabular}{ccccc}
\hline \multirow{2}{*}{$\begin{array}{c}\text { Concrete } \\
\text { strength grade }\end{array}$} & \multicolumn{4}{c}{ Per cubic meter of concrete material consumption } \\
\cline { 2 - 5 } & Water(kg) & Cement(kg) & Sand(kg) & Stone(kg) \\
\hline C25 & 180 & 312 & 889 & 964 \\
C30 & 200 & 408 & 896 & 896 \\
\hline
\end{tabular}

Table2 The admixture in subway tunnel lining concrete

\begin{tabular}{cccc}
\hline \multirow{2}{*}{\begin{tabular}{c} 
Concrete strength $\begin{array}{c}\text { Per cubic meter of concrete admixture, the dosage of admixture } \\
\text { grade }\end{array}$ \\
\cline { 2 - 4 }
\end{tabular}} & $\begin{array}{c}\mathrm{JC}-2 \\
\text { water reducer }(\mathrm{kg})\end{array}$ & $\begin{array}{c}\text { DM-F } \\
\text { accelerator }(\mathrm{kg})\end{array}$ & Fly ash(kg) \\
\hline C25 & 5.90 & - & 55.00 \\
C30 & - & 16.32 & - \\
\hline
\end{tabular}

\section{Curing technology}

In this paper, according to GB/T50081-2002 stipulated the way of concrete block maintenance,and put the concrete block into the temperature of $(20 \pm 2) \quad{ }^{\circ} \mathrm{Ca}(\mathrm{OH}) 2$ saturated solution curing $28 \mathrm{~d}$.

\section{Specimen grouping}

Test will be divided into 40 groups, and each group has three test block. These test blocks are put into $\mathrm{Na}_{2} \mathrm{SO}_{4}$ corrosive solution under wet-dry cycling, using the clear water as a comparison group.It is shown in Table 3.

Table3 Specimen grouping

\begin{tabular}{|c|c|c|c|c|c|c|}
\hline $\begin{array}{l}\text { Serial } \\
\text { number }\end{array}$ & $\begin{array}{c}\text { Lining } \\
\text { concrete } \\
\text { type }\end{array}$ & $\begin{array}{c}\text { Lining } \\
\text { concrete } \\
\text { strength } \\
(\mathrm{Mpa})\end{array}$ & $\begin{array}{c}\text { Test } \\
\text { environment }\end{array}$ & $\begin{array}{l}\text { Specimen } \\
\text { size }(\mathrm{mm})\end{array}$ & $\begin{array}{c}\text { component } \\
\text { number }\end{array}$ & number \\
\hline A & C25 & 30.06 & $\begin{array}{c}\mathrm{Na}_{2} \mathrm{SO}_{4} \\
(15 \%)\end{array}$ & $100 \times 100 \times 100$ & $10 \times 3$ & 30 \\
\hline A & $\mathrm{C} 25$ & 30.06 & Clear water & $100 \times 100 \times 100$ & $10 \times 3$ & 30 \\
\hline B & C30 & 37.52 & $\begin{array}{c}\mathrm{Na}_{2} \mathrm{SO}_{4} \\
(15 \%)\end{array}$ & $100 \times 100 \times 100$ & $10 \times 3$ & 30 \\
\hline B & C30 & 37.52 & Clear water & $100 \times 100 \times 100$ & $10 \times 3$ & 30 \\
\hline
\end{tabular}

\section{$\mathrm{Na}_{2} \mathrm{SO}_{4}$ solution corrosion states of different age}

Preliminary stage of corrosion, several white crystalline precipitate dry-wet circulation block, block surface appear white marks.As the test progressed, expand the area of white trace, explain the corrosion solution has been to enter inside the block.It is shown in Fig.1.
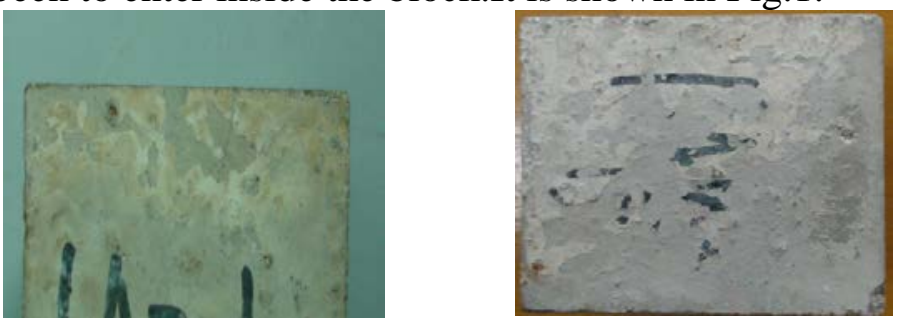
Fig.1Preliminary-stage test phenomenon of corrosion

To continue with the corrosion test, in the test medium, after some dry-wet alternate cycle, the color of test block to deepen. The edges can already see the collapse, the mortar off situation.As the corrosion to continue, microfractures expand gradually, and gradually formed obvious cracks.It is shown in Fig.2.
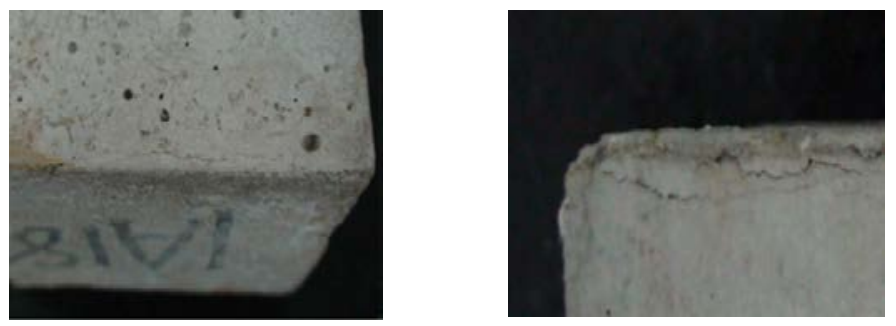

Fig.2 Mid-stage test phenomenon of corrosion

Late corrosion, the internal erosion that corrosion solution to the concrete makes the test block color turns to yellow. The middle of the crack has been generating obvious cracks. Some sand lose the effect of cementation and fall off, causing uneven surface, and surface hardness is decline seriously. Test block corner interface shape is irregular, and some performance index both are decline. In the end, the outer layer of the test block is get to crisp, and integrity is suffered heavy damage. Illustrate sulfate corrosion is more obvious.It is shown in Fig.3.
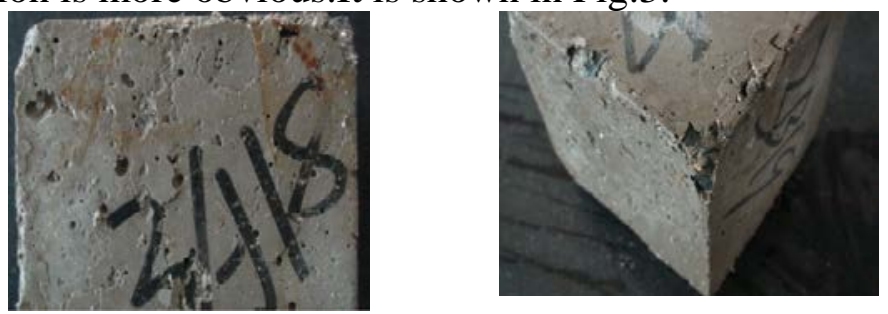

Fig.3 Late-stage test phenomenon of corrosion

\section{Ultrasonic method of strength-measuring curves was analyzed}

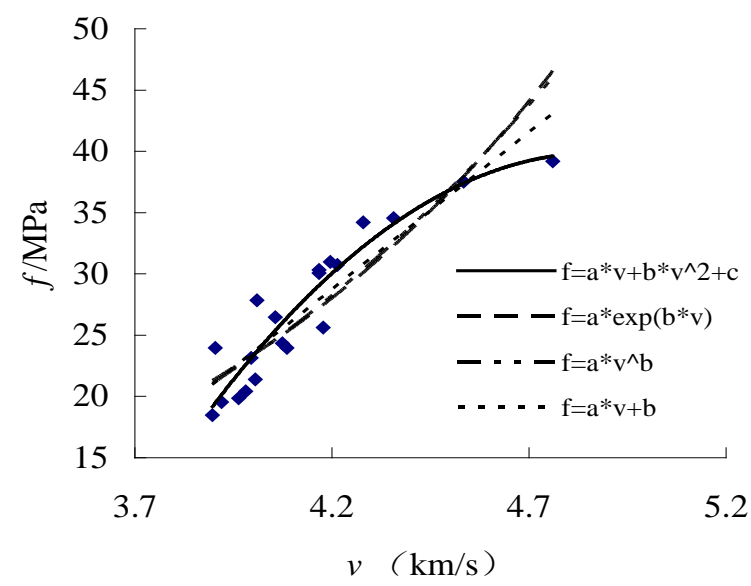

Fig.4 Regression formula of compressive in ultrasonic method

Fig.4 shows that polynomial function, linear function, power function and exponential function regression formula, and correlation coefficients were $0.94,0.91,0.89,0.94$. The average relative error $(\delta)$ is $6.40 \%, 8.57 \%, 9.05 \%, 9.37 \%$.The relative standard deviation ( ${ }^{e_{\mathrm{r}}}$ ) is 8.49\%,9.64\%,10.31\%,10.72\%.It is shown in Table 4.

Polynomial function regression formula is better, second type linear function and exponential fu nction regression formula, so it is recommended to use polynomial as ultrasonic measurement curves after the tunnel lining concrete under sulfate corrosion. 
Table4 The monadic regression results of ultrasonic wave velocity and compressive strength

\begin{tabular}{ccccc}
\hline Formula & Regression formula & $\mathrm{R}$ & $\delta$ & $e_{r}$ \\
\hline 1 & $f=-477.15+212.25 v-21.783 v^{2}$ & 0.94 & $6.40 \%$ & $8.49 \%$ \\
2 & $f=-79.017+25.657 v$ & 0.91 & $8.57 \%$ & $9.64 \%$ \\
3 & $f=0.104 v^{3.9052}$ & 0.89 & $9.05 \%$ & $10.31 \%$ \\
4 & $f=0.6252 e^{0.9055 v}$ & 0.88 & $9.37 \%$ & $10.72 \%$ \\
\hline
\end{tabular}

\section{Conclusions}

This experiment using the ultrasonic nondestructive testing method, and choose linear function, power function, exponential function and polynomial function regression formula.The ultrasonic wave velocity, springback value and compressive strength of subway tunnel lining concrete in the dry-wet alternate under the sodium sulfate solution and water for regression analysis, draw the following conclusions:

Using linear function, power function, exponential function and polynomial function regression formula curve, the study on tunnel lining concrete compressive strength conversion, as a whole,

polynomial function formula of accuracy is best.

In the methods of ultrasonic nondestructive testing, the precision of multiple parameter synthesis method regression formula is higher than the precision of single parameter method of ultrasonic and rebound method regression formula.

After be eroded by sodium sulfate solution of the tunnel lining concrete, nondestructive tests the regression curve that the polynomial function and linear function formula is better to return than the other.

\section{Acknowledgements}

The Project of National Key Techology R\&D Program in the 12th Five year Plan of China (2011BAJ10B04)

\section{References}

[1] B.Nilsen, T and Aven. Models and model uncertainty in the contex of risk analysis[J]. Reliability Engineering and System Safety,79 (2) : 309-317.

[2] Reilly.JJ. Management process for complex underground and tunneling project.Tunneling Underground[J]. Space Technollgy , 2000, pp: 31-44.

[3] T.W.Mellors.D.Southcott. A Code of practice for tunneling.Tunneling and Underground Space Technology[J]. 2004 (19) : 335-336.

[4] R.J.Flatt. Salt damage in porous materials: how high supersaturations are generated[J] J.Cryst.Growth, 242 (2002) 435-454.

[5] A.Costa J. Appleton.Chloride penetration into concrete in marine envronment-Part I:Main Parameters affecting ehloride Peneteration[J]. Materials and Structures:1999, 32 (4) : 252-259. 